Article

\title{
Perceptual-Motor Skills Reconstruction Program Improves Executive Functions in Children with Attention-Deficit/Hyperactivity Disorder
}

\author{
Sakineh Soltani Kouhbanani ${ }^{1, *}$ and Aribert Rothenberger ${ }^{2} \mathbb{D}$ \\ 1 Department of Educational Science, Ferdowsi University of Mashhad, Azadi Square, \\ Mashhad 9177948974, Iran \\ 2 Clinic for Child and Adolescent Psychiatry and Psychotherapy, University Medical Center Goettingen, \\ 37075 Goettingen, Germany; arothen@gwdg.de \\ * Correspondence: s.soltani@ferdowsi.um.ac.ir
}

check for updates

Citation: Soltani Kouhbanani, S.; Rothenberger, A. Perceptual-Motor Skills Reconstruction Program Improves Executive Functions in Children with

Attention-Deficit/Hyperactivity Disorder. Sustainability 2021, 13, 6210. https://doi.org/10.3390/su13116210

Academic Editors: Trinidad García and Celestino Rodriguez

Received: 18 March 2021

Accepted: 27 May 2021

Published: 31 May 2021

Publisher's Note: MDPI stays neutral with regard to jurisdictional claims in published maps and institutional affiliations.

Copyright: (c) 2021 by the authors. Licensee MDPI, Basel, Switzerland. This article is an open access article distributed under the terms and conditions of the Creative Commons Attribution (CC BY) license (https:// creativecommons.org/licenses/by/ $4.0 /)$.

\begin{abstract}
Objective: Many children suffering from attention-deficit/hyperactivity disorder (ADHD) show problems in executive functions (EF), which reflect neuronal pathways from perception to controlled action. Treatment approaches that improve executive functions may prevent a negative cycle of failures in students. Hence, this research aims to study the efficacy of the perceptualmotor skills reconstruction program on EF in children with ADHD while considering cognitive flexibility, abstract verbal skills, response inhibition, and working memory. Also, its effect on clinical ADHD symptoms should be considered. Method: The research design included pretest, posttest, and a follow-up after six months. The sample included third-grade school children with ADHD (50 students, aged 8-10 years, boys and girls) who were referred to the Child Psychology Clinic, Iran, Mashhad 2018-2019. After clinical assessment for ADHD, children were randomly assigned to an experimental $(n=25)$ and a waiting control $(n=25)$ group. The experimental group received the perceptual-motor skills reconstruction program for 16 sessions (three times per week, i.e., five weeks and one session in the sixth week). Delis-Kaplan executive function system (D-KEFS) was applied at three measurement points (M1-3) in order to test for changes over time. Results: Data analysis (analysis of covariance (ANCOVA) with post-hoc-testing) showed that there was a significantly better performance of experimental versus waiting control group at posttest (M2) and follow-up (M3) for cognitive flexibility $(\mathrm{t}(24)=4.9, \mathrm{df}=14, p<0.0001)$, abstract verbal skills $(\mathrm{t}(24)=3.5, \mathrm{df}=14$, $p<0.004)$, response inhibition $(\mathrm{t}(24)=7.54, \mathrm{df}=14, p<0.0001)$ and working memory $(\mathrm{t}(24)=12.69$, $\mathrm{df}=14, p<0.004)$. Further, Conners-Scales-Score improved for the experimental group. Conclusions: Training with perceptual-motor skills reconstruction program clearly improved the trained variables (i.e., cognitive flexibility, abstract verbal skills, response inhibition, and working memory) and clinical symptoms of the children with ADHD. The obtained training may lead in practice to better preconditions for successfully handling daily tasks at school and in society.
\end{abstract}

Keywords: perceptual-motor skills reconstruction program; cognitive flexibility; abstract verbal skills; response inhibition; working memory; attention deficit hyperactivity disorder (ADHD); children

\section{Introduction}

Attention deficit hyperactivity disorder (ADHD) is one of the most common neurodevelopmental disorders in childhood (with a worldwide prevalence of approximately 5\%). ADHD is classified into three different types (according to DSM-5 now "presentations"): inattentive type, hyperactive-impulsive type, combination type. It is characterized by psychosocially impairing attention-deficit, hyperactivity, and impulsivity, which in many cases is complicated by associated psychopathologies like emotional and conduct problems [1]. Shooshtary et al. [2] conducted a study in Iran and found that the prevalence of ADHD was $8-12 \%$ among Iranian children. Primary treatments for ADHD are either 
pharmacological (e.g., stimulants) or psychological (e.g., cognitive-behavioral therapy) approaches, where medication shows a higher effect size, at least in the short-term [3]. Also, physical activity seems to have positive effects on psychopathological symptoms in ADHD, probably via the noradrenergic neurotransmitter system. Many children with the diagnosis of ADHD experience impaired executive functions. Thus, some researchers believe that ADHD symptoms are more or less due to impairment of executive functions [4]. These cognitive functions are related to important neuronal-cognitive circuitries and implicate a critical role in guiding and controlling the behavior, including autonomy, inhibition, strategic planning, cognitive flexibility, time perception, impulse control, and working memory [5]. Besides, executive functions can greatly influence the performance of learning tasks, intelligent actions, and academic issues [6]. Supporting this logic, Willcutt et al. [7] included 83 studies in their meta-analytic research and showed that children and adults with ADHD had significant impairments in executive functions compared to the cases without ADHD.

The estimated effect size across all measures was in the medium range (0.46-0.69), but the domains of working memory, response inhibition, vigilance, and planning appeared to be the strongest and most matched effect among the others [8]. Another study [4] stated that the most stable and strongest executive dysfunction in people with ADHD was obtained in the measurements of response inhibition, working memory, and planning. This study included Wisconsin's card sorting test, the Stroop color and word test (SCWT), and the continuous performance test. According to the results of the above research, the experimental group's scores on the working memory and visual attention and London Tower Test were lower than expectations. Planning ability has been defined as the ability to identify and arrange the required steps and elements to make a plan or reach a goal. A deficiency in planning ability is strongly related to ADHD [9]. Moreover, response inhibition refers to a quick stopping of behavior in response to variable environmental requirements. The concept is one of the basic components of self-regulation. The ADHD children displayed problems with selective attention processing, an ability to allocate attention to a class of information and ignore, at the same time, other information which also demands activities of the central executive system [10]. It can be agreed, that in ADHD cognitively guided self-regulation and motor coordination are disturbed and thus cognitive-behavioral therapy and physical activity training could be supportive to improve the clinical picture and psychosocial functioning.

Given that ADHD often negatively targets both academic and social skills, one should pay full attention to timely interventions with no or little adverse effects; e.g., reinforcing executive functions, and thus strengthen self-regulation [11]. Childhood and adolescence psychiatric disorders affect subsequent stages; early diagnosis of these disorders, such as attention-deficit/hyperactivity disorder (ADHD), is necessary. This is more in demand since about $20 \%$ of children do not fully profit from guideline-suggested interventions like pharmacotherapy and behavior therapy.

Hence, there is still a need to expand the treatment armamentarium of ADHD. The perceptual-motor skills reconstruction program approach tries to modify the perceptualmotor system. The improvement of perceptual deficits via a cognitive approach may help to improve certain daily needed skills including symbolization, abstraction, verbal expression, reading, etc. [12]. This approach assumes that children are basically sensitive to external stimuli, but (because their EF is still developing) may not be able to systematically organize, interpret and handle the received stimuli at a higher level of cognition for better self-regulation of their behavior. In children with ADHD who show a delay in neuronal development and a low level of EF, it seems reasonable to conduct studies on this issue, in order to nurture their neuronal plasticity for better brain-behavior development. Hence, the present research aims to investigate the first time the efficacy of the perceptual-motor skills reconstruction program in the EF-areas of cognitive flexibility, abstract verbal skills, response inhibition, and working memory in children with ADHD; expecting a practically relevant improvement in the long term. 
The neurobiological basis for this may be seen, for example, in the significant effect of perceptual-motor training on brain electrophysiological measures, including increased amplitudes and shorter latencies of the P3 event-related potential component, which demonstrates more efficient and faster cognitive processing. According to the aforementioned studies, cognitively challenging physical activities have a greater effect on EFs in healthy children than cardiovascular physical training. T However, there is still an ongoing debate about the best strategies to improve EFs in children with ADHD and the types of cognitively demanding exercises have not been precisely determined. So far, the cognitivephysical activity approach has not been used to test for the improvement of EFs in children with ADHD. In view of this, the present study attempts (as a proof of principle) to explore the efficacy of perceptual-motor intervention in children with ADHD. In particular, this study investigates the effect of perceptual-motor training on EFs in children with ADHD in comparison with a waiting control group of matched children with ADHD. It is hypothesized that measures of EFs will be improved in participants in the perceptual-motor training group at the post-test and follow-up.

\section{Method}

\subsection{Study Design}

The present study is a pretest-posttest and follow-up design (measurement points M1, M2, and M3) with a treatment/experimental and a waiting control group. The sample includes all the elementary school children with attention-deficit/ hyperactivity disorder who were referred to the Child Psychology Clinic, Iran, Mashhad in 2018-2019.

\subsection{Sample}

After assessment for expert-confirmed ADHD, 50 children were selected and were randomly assigned into experimental and control groups. Analysis showed that the total sample size of $\mathrm{n}=50$, critical $\mathrm{t}$ of 1.701 , and actual power of 0.95 are achieved in this study. The average age is 8.1 years for all participants with ADHD, consisting of 32 boys and 18 girls ( 15 boys, 10 girls in the experimental group, and 17 boys, 8 girls in the control group). The characteristics of the participants are given in Table 1. All participants in the experimental group received the perceptual-motor skills reconstruction training program for 16 sessions of $45 \mathrm{~min}$ each (three times per week). The waiting control group received routine care only but was equally tested at M2 and M3.

Table 1. Characteristics of the participants.

\begin{tabular}{|c|c|c|}
\hline & Experimental Group & Control Group \\
\hline Number of children & 25 & 25 \\
\hline Gender & 10 girls, 15 boys & 8 girls, 17 boys \\
\hline Average age & 8.65 & 8.85 \\
\hline Age range & $8-10$ years old & $8-10$ years old \\
\hline Age Standard deviation (SD) & 0.13 & 0.15 \\
\hline Average IQ & 103 & 101 \\
\hline Average Conners-scores & 71 & 70 \\
\hline Average monthly income of the family & $455 \$$ & $481 \$$ \\
\hline \multirow{3}{*}{ Educational level of the mothers } & 7 (postgraduate degree) & 5 (postgraduate degree) \\
\hline & 10 (undergraduate degree) & 13 (undergraduate degree) \\
\hline & 8 (no higher education degree) & 7 (no higher education degree) \\
\hline
\end{tabular}

\subsection{Inclusion and Exclusion Criteria}

The inclusion criteria for this training were: diagnosis of ADHD after a clinical assessment performed by a board-certified clinical psychologist; including a clinical interview, Conners-Scale, and an IQ-Test. Participants fulfilled all the following criteria:

- No pharmacotherapy within the last three months.

- First referral to the clinic three months after discontinuing any treatment.

- Moderate and above-average intelligence (based on the Wechsler intelligence scale: $\mathrm{IQ}=100$ to $\mathrm{IQ}=120$ ). 
- Elementary school students.

- Aged between 8 and 10 years old.

- No severe medical (somatic/mental) illnesses

If the participating children had the following criteria, they were excluded from the assessment and treatment during the ongoing program:

- Absence of more than two sessions during the course

- Lack of proper cooperation and matching with other children

It has to be noted that during our tests, no children showed up with these exclusion criteria, and therefore, no one was excluded from the program.

\subsection{Measuring Tools}

Demographic profile: this profile includes some demographic variables, such as age, educational level, gender, medication, etc. designed by the researcher.

Clinical interview: to ensure the presence of ADHD in students who were diagnosed via completing the Conner's rating scale parent form, we used the revised fifth edition criteria of the diagnostic and statistical manual of mental disorders (DSM-5 APA 2018).

Conner's parent rating scale-revised: This scale was developed by [13] to assess the symptoms of ADHD. The questionnaire (containing 48 items) is completed by parents and the scoring procedure rated on a four-point Likert scale. The validity and reliability of this scale were confirmed by [12]. The retest reliability coefficient and Cronbach's alpha coefficient for the total score were 0.58 and 0.73 , respectively. In this study, the reliability and validity coefficients for this scale were 0.74 and 0.76 , respectively.

Delis-Kaplan Executive Function System: This test was developed by [14] for measuring executive functions. This test is a visual and neuropsychological test, which includes nine sub-tests, and is used to evaluate the verbal and non-verbal executive functions among children and adults aged 8 to 90 years old, which is administered within $90 \mathrm{~min}$. According to the goals of the present research, eight sub-tests (i.e., 1: trail making test, 2: verbal fluency test, 3: design fluency test, 4: Stroop color word test, 5: card-sorting test, 6: tower of London test, 7: the twenty questions test, and 8: word context test) were used to evaluate cognitive flexibility, abstract verbal skills, response inhibition, and working memory. The validity and reliability of this scale were confirmed by [14]. In the present research, the reliability and validity of the total scale were 0.79 and 0.78 , respectively.

\subsection{Procedures}

This study was approved by the Review Board of our university. The goals of the study were explained to the parents of participants and they filled out a written consent and permission form. In the first phase of the study, while identifying students with ADHD by clinical assessment, mothers were administered the Conners Parent Rating Scale. In the second phase of the study, participants who took the Delis-Kaplan executive function system's test (experimental and control groups) were invited for the pretest. In the third phase, the experimental group received the perceptual-motor skills training in sixteen sessions of 45-min each which were held three times per week. At the same time, the control group received routine care in their institution. During the period between M2 and M3, both groups received routine care, which was identical in both groups (including the period between M1 and M2 for the waiting control group). The routine care included nonstudy-related services such as educational programs, but no cognitive-behavioral therapy and no medication. Therefore, the control group may be considered as a passive control group. One week after the last training session of the experimental group, we administered posttest to both the control and experimental group to assess dependent variables again (M2). Six months after the completion of sessions, the experimental and control group were re-tested as the follow-up (M3). After collecting data from the posttest and followup, we offered an identical intervention with the perceptual-motor skills training to the control group. 


\subsubsection{Evaluative Procedures}

For data collection, first to diagnose Attention Deficit Hyperactivity Disorder Participants received an ADHD diagnosis if they met criteria for ADHD (Combined type) using the Diagnostic Interview for Children and Adolescents, Fifth Edition. We used two inventories namely Conners Parent Rating Scale (see Table 1) and Delis-Kaplan Executive Function System (D-KEFS). The participants of the Delis-Kaplan executive function system test (experimental and control groups) were invited for the pretest. Training for the experimental group consisted of the perceptual-motor skills reconstruction program (45 $\mathrm{min}$ ) for 16 sessions (three times per week), but no intervention was assigned for the control group participants. A week after the last training session was completed in both experimental and control groups, posttests were conducted for the Delis-Kaplan Executive Function System (D-KEFS). The same holds true for follow-up.

\subsubsection{Treatment Procedures}

The perceptual-motor skills reconstruction program: The methodology of intervention chosen for the current study is based on Werner-Rainey training programs (2014). Variables trained are explained as follows. [11] and include some elements similar to an efficacious sensorimotor training in ADHD in [15]. This intervention strategy includes a combination of balanced exercises that take into account tone awareness, space awareness, shape perception, and visual and auditory perceptions. We used the assistance of three PA teachers in this program. At each station, a teacher monitored and guided children on how to perform these exercises based on their skill level. The experimental group received 16 sessions (45 min each), which consisted of three training sessions per week for the reconstruction of perceptual-motor skills, but the control group received routine care only. The practical intervention methods used in this investigation are described in Table 2.

Table 2. Instructions for the 16 Sessions ( $45 \mathrm{~min}$ each) of the perceptual-motor training.

\begin{tabular}{|c|c|c|}
\hline Session & Title & Description \\
\hline 1 & Training of balance & $\begin{array}{l}\text { (1) Balance puzzles, (2) balance stick, (3) balance board, (4) jump board, (5) rolling } \\
\text { board, (6) spinning board, (7) large tube, (8) scooter board, (9) walking with cans, } \\
\text { (10) walking ladder. }\end{array}$ \\
\hline 2 & $\begin{array}{l}\text { Other exercises relating } \\
\text { to the balance training }\end{array}$ & $\begin{array}{l}\text { (1) Balance puzzles, (2) balance stick, (3) balance board, (4) jump board, (5) rolling } \\
\text { board, (6) spinning board, (7) large tube, (8) scooter board, (9) walking with cans, } \\
\text { (10) walking ladder. }\end{array}$ \\
\hline 3,4 & $\begin{array}{l}\text { Awareness training, and the role } \\
\text { of organs }\end{array}$ & $\begin{array}{l}\text { (1) Pip cleaner in the form of a human, (2) human puzzle, (3) drawing body parts, } \\
\text { (4) felt board with right and left-hand shapes, (5) running left-hand commands on } \\
\text { the right leg and vice versa, (6) mirror and blackboard. }\end{array}$ \\
\hline 5,6 & $\begin{array}{l}\text { Spatial awareness training } \\
\text { (location) }\end{array}$ & $\begin{array}{l}\text { (1) Diagram and reading arrows' directions, (2) flooring block, (3) similarities and } \\
\text { differences puzzle, (4) orientation, (5) following directions, (6) child's bending and } \\
\text { balancing on the geometric shapes, (7) nailed board. }\end{array}$ \\
\hline 7,8 & Training of shape perception & $\begin{array}{l}\text { (1) Geometric barriers, (2) sand, clay, and painting with fingers, (3) mold, (4) shape, } \\
\text { letter, and number dominoes, (5) puzzle, (6) shape exercises from the background, } \\
\text { (7) design and color play, (7) Tangram }\end{array}$ \\
\hline 9,10 & Visual perception training & $\begin{array}{l}\text { (1) Marble tracking, (2) pendulum ball, (3) timer, (4) eye rotation, (5) penlight, (6) the } \\
\text { maze, (7) what's forgotten? (8) shape stability exercises, (9) visual memory exercises, } \\
\text { (10) thread and bead, (11) sharp-eyed game, (12) hidden images. }\end{array}$ \\
\hline 11,12 & Auditory perception training & $\begin{array}{l}\text { (1) Audible tape, (2) kick, clap and snap, (3) list of alphabetic characters, (4) making } \\
\text { sentences by adding a word to another, (5) storytelling and repeating some of the } \\
\text { story sections, (6) converse speaking, (7) babbles practice, (8) clean audio cans. }\end{array}$ \\
\hline 13,14 & $\begin{array}{l}\text { Touch-kinetic perception } \\
\text { training }\end{array}$ & $\begin{array}{l}\text { (1) Skin feelings experiences, (2) clay and painting with fingers, (3) touchpad boxes, } \\
\text { play dough with closed eyes, (5) estimation games. }\end{array}$ \\
\hline 15,16 & $\begin{array}{l}\text { Coordination of eye and hand, } \\
\text { eye and leg, } \\
\text { subtle motor actions }\end{array}$ & $\begin{array}{l}\text { (1) Rectangular wooden rods, }(2) \text { round rods, }(3) \text { depth perception board, (4) } \\
\text { recognition by touching, (5) assembling rockets, (6) rotating the ring, (7) balloon, } \\
\text { (8) bubble making, (9) candle and water gun, (10) nuts and bolts, (11) paper and } \\
\text { pencil exercises. }\end{array}$ \\
\hline
\end{tabular}




\subsection{Ethical Approval}

This study was approved by the Review Board of Ferdowsi University of Mashhad (IR.UM.REC. 1398.149). The study was conducted in compliance with the principles of the Declaration of Helsinki.

Written informed consent was given by the parents and assent by the children.

\subsection{Data Analysis}

Results were analyzed using statistical package SPSS, version 22.0 (IBM Crop). After determining the normality, we continued the analysis using paired $t$-test and ANCOVA. Statistical tests with $p$-values less than 0.05 , indicated significant training improvement of executive functions in children.

The descriptive statistics used in data analysis consisted of means (M) and standard deviations (SD) for both groups. To compare the difference between the groups, the independent $t$-test was employed. Then, repeated measures ANCOVAs were conducted to examine the effect of perceptual-motor skills training programs on dependent variables. We checked typical assumptions of ANCOVA, including normality and homogeneity of variance using Boxplot and Q-Q plot (residuals vs. fitted values). Bonferroni's post hoc test was used to detect inter-group differences at different times. The analysis was performed using SPSS, version 22.0 (IBM Crop) and $p$-values less than 0.05 , indicated significant training improvement of executive functions in children.

\section{Results}

The research question was: "does the perceptual-motor skills reconstruction program have any positive effect on cognitive flexibility, abstract verbal skills, working memory, and response inhibition of children with ADHD?". As shown in Table 3, all investigated executive functions' components in the experimental group obtained a higher mean value than those for the waiting control group at posttest and follow-up; while at pretest (baseline) small differences seem to be negligible. Beyond the improvement of the executive functions of the children, the results in Table 3 show also a moderate improvement of the mean value of the Conners parent rating scale.

Table 3. Mean and standard deviation (SD) of the research variables.

\begin{tabular}{|c|c|c|c|c|c|c|c|c|c|c|c|c|c|}
\hline \multirow{3}{*}{ Variable } & \multirow{3}{*}{ Component } & \multicolumn{6}{|c|}{ Control Group } & \multicolumn{6}{|c|}{ Experimental Group } \\
\hline & & \multicolumn{2}{|c|}{ Pre } & \multicolumn{2}{|c|}{ Post } & \multicolumn{2}{|c|}{ Follow Up } & \multicolumn{2}{|c|}{ Pre } & \multicolumn{2}{|c|}{ Post } & \multicolumn{2}{|c|}{ Follow Up } \\
\hline & & $\mathbf{M}$ & SD & $\mathbf{M}$ & SD & $\mathbf{M}$ & SD & $\mathbf{M}$ & SD & $\mathbf{M}$ & SD & $\mathbf{M}$ & SD \\
\hline \multirow{5}{*}{$\begin{array}{l}\text { Executive } \\
\text { functions }\end{array}$} & Cognitive flexibility & 17.54 & 9.17 & 18.05 & 11.12 & 16.54 & 10.54 & 19.65 & 9.98 & 75.5 & 13.89 & 71.13 & 11.43 \\
\hline & Abstract verbal skills & 32.18 & 13.12 & 31.16 & 11.14 & 31.16 & 12.54 & 30.64 & 11.56 & 45.25 & 10.49 & 41.32 & 10.65 \\
\hline & Response inhibition & 22.78 & 11.17 & 21.6 & 11.15 & 21.6 & 11.66 & 23.78 & 11.84 & 42.3 & 6.82 & 41.43 & 8.54 \\
\hline & Working memory & 16.65 & 10.87 & 18.75 & 10.11 & 18.75 & 10.35 & 18.54 & 10.42 & 35.9 & 10.06 & 31.42 & 10.53 \\
\hline & Conners Parent Rating Scale & 70 & 2.5 & 69 & 2.9 & 69 & 3 & 71 & 3.1 & 56 & 4.8 & 55 & 4.2 \\
\hline
\end{tabular}

Assumptions of data distribution normality and homogeneity of variances in the groups were examined. The Kolmogorov-Smirnov test detected that the distribution of data relating to the scores on EF's components was normal and was not at the significant level $(p>0.05)$. Furthermore, the result of the Box's M showed that there was no statistically significant difference $(p>0.256, \mathrm{~F}=1.114)$, indicating that the covariance-variance matrix was homogenous. Supporting the test assumptions in this study, we later used the ANCOVA statistical model for the above research hypothesis testing.

ANCOVA with pre-test scores as the covariates was used to examine the treatment effects between groups. The results (Table 4 ) from the post-test scores of cognitive flexibility components, abstract verbal skills, response inhibition and working memory indicated that after modifying the pre-test scores, there was a significant group effect upon cognitive flexibility $(F(1,47)=25.811, p<0.0001$, partial $\eta 2=0.495)$, abstract verbal skills $(F(1,47)=22.279$, 
$p<0.0001$, partial $\eta 2=0.445)$, response inhibition $(\mathrm{F}(1,47)=34.115, p<0.0001$, partial $\eta 2=0.543)$ and working memory $(\mathrm{F}(1,47)=42.046, p<0.0001$, partial $\eta 2=0.603)$. This means that there was a statistically significant difference between the groups.

Table 4. ANCOVA for waiting control group compared to the experimental group according to EF.

\begin{tabular}{|c|c|c|c|c|c|c|c|}
\hline Variables & Source & $\begin{array}{l}\text { Sum of } \\
\text { Squares }\end{array}$ & $\begin{array}{l}\text { Mean } \\
\text { Square }\end{array}$ & $\mathbf{F}$ & Sig & $\begin{array}{c}\text { Partial Eta } \\
\text { Squared }\end{array}$ & $\begin{array}{c}\text { Observed } \\
\text { Power }\end{array}$ \\
\hline \multirow{3}{*}{$\begin{array}{l}\text { Cognitive } \\
\text { flexibility }\end{array}$} & Pretest & 2.234 & 2.234 & 0.066 & 0.804 & 0.004 & 0.054 \\
\hline & Group & 891.456 & 891.456 & $25.811^{* *}$ & 0.001 & 0.495 & 0.994 \\
\hline & Error & 938.565 & 33.343 & & & & \\
\hline \multirow{3}{*}{$\begin{array}{c}\text { Abstract } \\
\text { verbal skills }\end{array}$} & Pretest & 278.397 & 278.397 & $21.275^{* *}$ & 0.001 & 0.444 & 0.934 \\
\hline & Group & 285.545 & 285.545 & $22.279 * *$ & 0.001 & 0.445 & 0.994 \\
\hline & Error & 354.245 & 12.845 & & & & \\
\hline \multirow{3}{*}{$\begin{array}{l}\text { Response } \\
\text { inhibition }\end{array}$} & Pretest & 645.354 & 645.354 & $37.361^{* *}$ & 0.001 & 0.583 & 1.000 \\
\hline & Group & 633.564 & 633.564 & $34.115^{* *}$ & 0.001 & 0.543 & 1.000 \\
\hline & Error & 454.565 & 18.445 & & & & \\
\hline \multirow{3}{*}{$\begin{array}{l}\text { Working } \\
\text { memory }\end{array}$} & Pretest & 345.285 & 345.285 & 2.668 & 0.115 & 0.084 & 0.343 \\
\hline & Group & 5554.445 & 5554.445 & $42.046^{* *}$ & 0.001 & 0.603 & 1.000 \\
\hline & Error & 3545.845 & 131.645 & & & & \\
\hline
\end{tabular}

Pre-treatment scores (M1) were employed as the baseline and compared to the scores from post-treatment (M2) and six months of follow-up (M3). The results are shown according to Table 5 and Table 6. Paired $t$-tests were used to compare the pre-test and follow-up scores of the experimental group to determine the long-term difference of EFs after six months.

Table 5. Comparison of EFs scores of ADHD children of the experimental group $(n=25)$ between pre-test (M1) and follow-up (M3).

\begin{tabular}{cccccc}
\hline & $\begin{array}{c}\text { Mean of M1 } \\
\text { and M3 }\end{array}$ & $\begin{array}{c}\text { Standard } \\
\text { Deviation }\end{array}$ & t Value & $\begin{array}{c}\text { Degree of } \\
\text { Freedom }\end{array}$ & $p$-Value \\
\hline Cognitive flexibility & 10.46 & 8.27 & 4.9 & 24 & 0.0001 \\
Abstract verbal skills & 5.53 & 6.11 & 3.5 & 24 & 0.004 \\
Response inhibition & 11.2 & 5.74 & 7.54 & 24 & 0.0001 \\
Working memory & 42.73 & 13.04 & 12.69 & 24 & 0.0001 \\
\hline
\end{tabular}

Table 6. Comparison of EFs scores of ADHD children of the experimental group $(n=25)$ between post-test (M2) and follow-up (M3).

\begin{tabular}{cccc}
\hline Dependent Variables & Level & t Value & $p$-Value \\
\hline \multirow{2}{*}{ Cognitive flexibility } & Posttest & 0.902 & 0.36 \\
& Follow-up & 5.14 & $0.0001^{*}$ \\
\hline \multirow{2}{*}{ Verbal fluency } & Posttest & -1.3 & 0.2 \\
& Follow-up & 1.39 & 0.06 \\
\hline \multirow{2}{*}{ Response inhibition } & Posttest & 0.53 & 0.59 \\
& Follow-up & 3.43 & $0.001 *$ \\
\hline \multirow{2}{*}{ Working memory } & Posttest & 1.33 & 0.17 \\
& Follow-up & 5.15 & $0.0001 *$ \\
\hline
\end{tabular}

*p<0.0001.

Table 5 indicates that the EF variables were also significantly reduced after 6 months. Reduced EFs included cognitive flexibility $(\mathrm{t}(24)=4.9, \mathrm{df}=14, p<0.0001)$, abstract verbal skills $(\mathrm{t}(24)=3.5, \mathrm{df}=14, p<0.004)$, response inhibition $(\mathrm{t}(24)=7.54, \mathrm{df}=14, p<0.0001)$ and working memory $(\mathrm{t}(24)=12.69, \mathrm{df}=14, p<0.0001)$. The results support the long-term effect of training on the executive functions; even after stopping the treatment. 
At follow-up (M3) for cognitive flexibility, verbal fluency, response inhibition, and working memory, there was a statistically significant difference between the experimental and control groups $(p>0.025)$. The post-test and follow-up mean scores indicated that the mean of the experimental group (trained with the perceptual-motor skills reconstruction program) was higher than that of the waiting control group at follow-up.

\section{Discussion}

The study aimed to investigate the efficacy of the perceptual-motor skills reconstruction program on EFs, namely cognitive flexibility, abstract verbal skills, response inhibition, and working memory in children with ADHD. Moreover, the effects on clinical ADHD symptoms were tested to find out whether the ecological validity of this training exists. Our findings demonstrated that the executive functions of children with ADHD improved after completing the perceptual-motor skills reconstruction program training for 16 sessions. After the end of the treatment, these positive effects could be found stable at 6-months follow-up under routine care. Further, clinical ADHD symptoms decreased after the training and remained stable too.

Rapport et al. [16] suggested that attention deficits in ADHD create major psychosocial problems in these children because of affecting cognitive self-regulatory processes, specifically working memory. Therefore, addressing cognitive problems in children with ADHD is one of the main goals of the program. Nowadays, the importance of working memory has gained the attention of many researchers $[17,18]$. It refers to the ability to maintain information in mind while performing complex tasks and the ability to supervise the performance and evaluate the cognitive processes. This is supported by a study in children with ADHD whose cognitive-inhibitory processes were strengthened by a three-month training with mind maps metacognitive strategies [19]. Executive processing, including intention, planning, and activity inhibition, constantly needs working memory. From a structural point, the prefrontal cortex generally contributes to mediating executive function mechanisms, being a prerequisite for desired actions to be done successfully [20].

As for the perceptual-motor training, our results exhibited improvement in all aspects of EFs in the experimental group compared to the control group. These results are aligned with those reported in earlier studies on typically developing children. Fine and gross motor enrichment has a positive effect on mathematical problem-solving in typically developing children. Similarly, our results showed that perceptual-motor activity containing fine and gross motor training could improve EFs in children with ADHD. In addition, these findings support the idea that cognitively demanding physical exercises can improve cognitive processing [21]. The motor-cognition connection is reinforced by the engagement of neural regions during motor tasks, which are classically pertained to cognitive functions [21]. Training EFs through motor tasks generates positive changes in EFs, which could be linked to the growth of prefrontal and parietal activity. Serrien et al. demonstrated that identical brain regions seem to be engaged in both complex motor tasks and EFs tasks [22]. Additionally, this positive effect may be linked to electrophysiological measures of the brain, including increased amplitude and shorter latency of the P3 event-related potentials (ERPs) component, which exhibits more efficient and faster cognitive processing [23]. For the age range of students selected for this research, perceptual-motor activities seem to be effective physical activities in reinforcing attention, which is critical to the reinforcement of short and long-term memory due to the role of the cerebellum and frontal lobe in perceptual-motor tasks and cognition [24].

The results obtained in this study are in line with the results of several other authors [25-30], showing the efficacy of perceptual-motor skills training in improving the cognitive problems of children. The research results also suggest that the perceptual-motor skills reconstruction program may not only affect planning and organization of learning but also may have positive effects on time management and scheduling, setting a goal, self-control, and self-assessment, although more empirical evidence is needed. 
Children with ADHD often show problems with sensorimotor skills [15] as well as with EF issues [7,31]. According to our findings, the latter may be improved after perceptual-motor skills reconstruction program training. Specifically, this holds for cognitive flexibility, abstract verbal skills, response inhibition, and working memory. Hence, perceptual-motor activity training may be seen as a certain form of physical activity (mainly coordination) training combined with a cognitive training of self-regulation. This suggests that mainly cerebellum and frontal lobes may be involved in the applied perceptualmotor and cognitive tasks, although the true neurobiological mechanism behind this general improvement of self-regulation remains to be investigated. Finally, the value of the perceptual-motor skills training reaches beyond the trained cognitive parameters, since, in parallel, clinical ADHD symptoms improved.

There are several limitations of this study. First, there was a small age range and sample size. In addition, the effect of gender and parents' expectations and comorbidities were not controlled. Also, an active control group was not investigated. Therefore, generalization and specification of results must be done cautiously. It is suggested that future research considers these factors to get a more complete picture of the EF-training effects. On the other hand, the strength of this study is proof of principle that the training seems to work as expected, including the encouraging finding of a long-term effect of the EF-training. Moreover, according to the embodied cognition theory, cognitive processing is grounded in bodily experience. According to this perspective, cognition is a product of the brain, body, and environmental interactions when individuals engage in an action. Hence, it may vary by changing the activity. Cognitively demanding motor tasks can alter EFs and consequently learning and handling clinical symptoms. The results are in agreement with those reported by Picard and Strick (1996) according to which cognitively demanding motor tasks co-vary with the pattern of brain activation, and therefore the extent of information processing [32]. Greater cognitive demand for motor tasks requires more prefrontal and cerebellum activities during perceptual-motor training tasks [24]. Thus, it seems that this type of motor training requires more diversified frontal-dependent cognitive processes. Therefore, one should have a differentiated look, when analyzing the value of studies on physical activity in ADHD (unfortunately not done in meta-analyses cited by [1]; i.e., just cardiovascular training may lead to smaller/other effects than cognitive-sensorimotor training as it was applied in our study with the perceptual-motor skills reconstruction program.

\section{Conclusions}

The empirical results of the present pilot study suggest that the perceptual-motor skills reconstruction program training may lead to the improvement of EFs, namely cognitive flexibility, abstract verbal skills, response inhibition, and working memory in children with ADHD. This effect remained even after a follow-up of six months under routine care. In addition, the training had a positive effect on clinical ADHD symptoms. Considering the high prevalence of ADHD with its serious psychosocial impairments and the need for further treatment approaches, it seems necessary to provide easily accessible facilities even within educational environments. Specifically, for children with weaker cognitive flexibility, such training could strengthen their opportunity to show more of their cognitive potential. As an example, the perceptual-motor skills reconstruction program may be offered to children with ADHD. The present study had a number of limitations that should be noted. Besides, it was not controlled for associated psychopathologies, there was only a passive control group. Accordingly, future studies should include an active control group (e.g., with cardiovascular training) so that perceptual-motor training could be compared to other kinds of physical exercise. Also, future studies may assess the neural aspect of perceptual-motor training; for example, recording brain event-related potentials before and after the intervention could shed some light on the neural effect and thus help to better understand how brain mechanisms may translate perceptual-motor training effects to EF performance. 
Author Contributions: Conceptualization, Methodology, Investigation, Formal Analysis were done by S.S.K.; partly supervised by A.R.; Writing first draft and revisions were conducted jointly by S.S.K. and A.R. All authors have read and agreed to the published version of the manuscript.

Funding: This research received no external funding.

Data Availability: Due to the restrictions at our institute, the data for this cannot be shared.

Acknowledgments: All expenses of this research project were funded by the author and we did not receive any financial grant from a specific entity. We would like to thank the Welfare Organization of Khorasan Razavi and its branches. We are also grateful to the families who took part in our research. We also wish to thank teachers, coaches, and specialists who help us in the course of this study.

Conflicts of Interest: The authors declare no conflict of interest.

\section{References}

1. Faraone, S.V.; Banaschewski, T.; Coghill, D.; Zheng, Y.; Biederman, J.; Bellgrove, M.A.; Newcorn, J.H.; Gignac, M.; Al Saud, N.M.; Manor, I.; et al. The World Federation of ADHD International Consensus Statement: 208 evidence based conclusions about the disorder. Neurosci. Biobehav. Rev. 2021. [CrossRef] [PubMed]

2. Shooshtary, M.H.; Chimeh, N.; Najafi, M.; Mohamadi, M.R.; Yousefi-Nouraie, R.; Rahimi-Mvaghar, A. The prevalence of attention deficit hyperactivity disorder in Iran: A systematic review. Iran. J. Psychiatry 2010, 5, 88.

3. Catalá-López, F.; Hutton, B.; Núñez-Beltrán, A.; Page, M.J.; Ridao, M.; Macías Saint-Gerons, D.; Catalá, M.A.; Tabarés-Seisdedos, R.; Moher, D. The pharmacological and non-pharmacological treatment of attention deficit hyperactivity disorder in children and adolescents: A systematic review with network meta-analyses of randomised trials. PLoS ONE 2017, 12, e0180355. [CrossRef]

4. Holmes, J.; Gathercole, S.E.; Place, M.; Alloway, T.P.; Elliott, J.G.; Hilton, K.A. The di-agnostic utility of executive function assessments in the identification of ADHD in children. Child Adolesc. Ment. Health 2010, 15, 37-43. [CrossRef]

5. Blair, C. Developmental science and executive function. Curr. Dir. Psychol. Sci. 2016, 25, 3-7. [CrossRef]

6. Meltzer, L. Executive Function in Education: From Theory to Practice; Guilford Publication: New York, NY, USA, 2018.

7. Willcutt, E.G.; Doyle, A.E.; Nigg, J.T.; Faraone, S.V.; Pennington, B.F. Validity of the executive function theory of attentiondeficit/hyperactivity disorder: A meta-analytic review. Biol. Psychiatry 2005, 57, 1336-1346. [CrossRef]

8. Willcutt, E.G. The prevalence of DSM-IV attention-deficit/hyperactivity disorder: A meta-analytic review. Neurotherapeutics 2012, 9, 490-499. [CrossRef]

9. Boyer, B.E.; Geurts, H.M.; van der Oord, S. Planning skills of adolescents with ADHD. J. Atten. Disord. 2018, 22, 46-57. [CrossRef]

10. Alderson, R.M.; Rapport, M.D.; Kasper, L.J.; Sarver, D.E.; Kofler, M.J. Hyperactivity in boys with attention deficit/hyperactivity disorder (ADHD): The association between deficient behavioral inhibition, attentional processes, and objectively measured activity. Child Neuropsychol. 2012, 18, 487-505. [CrossRef]

11. Hallahan, D.P.; Pullen, P.C.; Kauffman, J.M.; Badar, J. Exceptional learners. In Oxford Research Encyclopedia of Education; Oxford Research Encyclopedias: Oxford, UK, 2020.

12. Asiaee, F.; Yamini, M.; Mahdian, H. The comparsion the effectiveness of Perceptual Skills Reconstruction and education executive functions (attention, planning, respose inhibition) on Working Memory, perceptual reasoning, and Math Performance of Students with Specific Math Learning disorder. J. Cogn. Psychol. 2018, 6, 61-70.

13. Conners, C.K.; Sitarenios, G.; Parker, J.D.; Epstein, J.N. The revised Conners' Parent Rating Scale (CPRS-R): Factor structure, reliability, and criterion validity. J. Abnorm. Child Psychol. 1998, 26, 257-268. [CrossRef]

14. Delis, D.C.; Kramer, J.H.; Kaplan, E.; Holdnack, J. Reliability and validity of the Delis-Kaplan Executive Function System: An update. J. Int. Neuropsychol. Soc. 2004, 10, 301-303. [CrossRef]

15. Banaschewski, T.; Besmens, F.; Zieger, H.; Rothenberger, A. Evaluation of sensorimotor training in children with ADHD. Percept. Mot. Ski. 2001, 92, 137-149. [CrossRef] [PubMed]

16. Rapport, M.D.; Orban, S.A.; Kofler, M.J.; Friedman, L.M. Do programs designed to train working memory, other executive functions, and attention benefit children with ADHD? A meta-analytic review of cognitive, academic, and behavioral outcomes. Clin. Psychol. Rev. 2013, 33, 1237-1252. [CrossRef] [PubMed]

17. Dahlin, K.I. Effects of working memory training on reading in children with special needs. Read. Writ. 2011, 24, 479-491. [CrossRef]

18. Sharifi, A.; Zare, H.; Heidari, M. Comparing Working Memory in Dyslexic and Normal Students. J. Learn. Disabil. 2013, 2, 6-17.

19. Natalia, K.A.K. The Influence of Metacognitive Strategies on the Improvement of Reaction Inhibition Processes in Children with ADHD. Int. J. Environ. Res. Public Health 2021, 18, 878.

20. Delis, D.C.; Kaplan, E.; Kramer, J.H.; Delis, D.; Kramer, J. Delis-Kaplan executive function system (D-KEFS). Exam. Man. 2001. [CrossRef]

21. Koutsandreou, F.; Wegner, M.; Niemann, C.; Budde, H. Effects of motor versus cardiovas-cular exercise training on children's working memory. Med. Sci. Sports Exerc. 2016, 48, 1144-1152. [CrossRef]

22. Serrien, D.J.; Ivry, R.B.; Swinnen, S.P. Dynamics of hemispheric specialization and integra-tion in the context of motor control. Nat. Rev. Neurosci. 2006, 7, 160. [CrossRef]

23. Polich, J. Updating P300: An integrative theory of P3a and P3b. Clin. Neurophysiol. 2007, 118, 2128-2148. [CrossRef] 
24. Budde, H.; Voelcker-Rehage, C.; Pietraßyk-Kendziorra, S.; Ribeiro, P.; Tidow, G. Acute coor-dinative exercise improves attentional performance in adolescents. Neurosci. Lett. 2008, 441, 219-223. [CrossRef]

25. Picard, N.; Strick, P.L. Motor areas of the medial wall: A review of their location and func-tional activation. Cereb. Cortex 1996, 6 , 342-353. [CrossRef] [PubMed]

26. Goldstein, B.H.; Obrzut, J.E. Neuropsychological treatment of dyslexia in the class-room setting. J. Learn. Disabil. 2001, 34, 276-285. [CrossRef] [PubMed]

27. Robertson, J. Neuropsychological intervention in dyslexia: Two studies on British pupils. J. Learn. Disabil. 2000, 33, 137-148. [CrossRef] [PubMed]

28. Lorusso, M.L.; Facoetti, A.; Molteni, M. Hemispheric, attentional, and processing speed factors in the treatment of developmental dyslexia. Brain Cogn. 2004, 55, 341-348. [CrossRef] [PubMed]

29. Pintrich, P.R. Multiple goals, multiple pathways: The role of goal orientationin learn-ing and achievement. J. Educ. Psychol. 2000, 92, 544. [CrossRef]

30. Nota, L.; Soresi, S.; Zimmerman, B.J. Self-regulation and academic achievement and resilience: A longitudinal study. Int. J. Educ. Res. 2004, 41, 198-215. [CrossRef]

31. Murphy, K.R.; Barkley, R.A.; Bush, T. Executive functioning and olfactory identifica-tion in young adults with attention deficithyperactivity disorder. Neuropsychology 2001, 15, 211. [CrossRef] [PubMed]

32. Stad, F.E.; Wiedl, K.H.; Vogelaar, B.; Bakker, M.; Resing, W.C.M. The role of cognitive flexibility in young children's potential for learning under dynamic testing con-ditions. Eur. J. Psychol. Educ. 2019, 34, 123-146. [CrossRef] 